SOUTHERN BRAZILIAN, JOURNAL OF CHEMISTRY

SOUTH. BRAZ. J. CHEM., Vol. 18, No.18, 2010

\title{
THERMAL DISAPPEARANCE KINETICS OF RADICALS FORMED DURING RADIOLYSIS IN POLYCRYSTALLINE SOLID STATE OF SODIUM WOLFRAMATE DIHYDRATE
}

\author{
Mihail Contineanu ${ }^{a}$, Adina-Elena Stanciu ${ }^{b}$, Iulia Contineanu ${ }^{c}$ and Ana Neacşu ${ }^{\mathbf{c}^{*}}$ \\ ${ }^{a}$ Faculty of Chemistry, University of Bucharest, 4-12 Regina Elisabeta Blvd., Bucharest, \\ ROMANIA 030018 \\ e-mail:mihconti@yahoo.com \\ b"Prof.Dr.Al.Trestioreanu" Institute of Oncology, Department of Carcinogenesis and \\ Molecular Biology, Sos. Fundeni, Nr.252, Sector 2, Bucharest, ROMANIA 022328 \\ e-mail: adinaelenastanciu@yahoo.com. \\ c Institute of Physical Chemistry "Ilie Murgulescu", 202 Spl. Independentei, Bucharest, \\ ROMANIA 060021 \\ e-mail: icontineanu@yahoo.com, anna_matache@yahoo.com
}

\begin{abstract}
A kinetic study of the $\mathrm{W}_{4}^{-}$radical, formed by gamma irradiation of polycrystalline $\mathrm{Na}_{2} \mathrm{WO}_{4} \cdot 2 \mathrm{H}_{2} \mathrm{O} \quad \mathrm{UCB}$ at room temperature has been performed using the EPR technique. A suitable mechanism for the formation of paramagnetic centers by irradiation and thermal annealing is proposed. The mechanism agrees well with the experimental kinetic data.
\end{abstract}

KEY WORDS: paramagnetic species, absorbed dose, thermal disappearance, radiolytical process, sodium wolframate.

\section{RESUMO}

Um estudo cinético do radical $\mathrm{W}_{4}^{-}$formado pela irradiação gama de $\mathrm{Na}_{2} \mathrm{WO}_{4} \cdot 2 \mathrm{H}_{2} \mathrm{O}$ UCB policristalino foi efetuado a temperatura ambiente usando ressonância paramagnética eletrônica (RPE). Um mecanismo adequado foi proposto para a formação de centros paramagnéticos pela irradiação e para o cozimento térmico. $O$ mecanismo proposto concorda com os resultados cinéticos experimentais.

PALAVRAS CHAVES: espécies paramagnéticas, processo radiolítico, dose absorvida, desaparecimento térmico, wolframato de sódio.

Corresponding e-mail: anna_matache@yahoo.com

VISIT OUR SITE: http://www.sbjchem.he.com.br 


\section{SOUTH. BRAZ. J. CHEM., Vol.18, No. 18, 2010 \\ Radiolysis of Sodium Wolframate UCB}

\section{INTRODUCTION}

The oxygenated compounds such as wolframates and parawolframates, where $\mathrm{W}$ is in the VI valence state, are not paramagnetic. Irradiation generates radicals in the VII and V valence state, that are trapped in the lattice and can be studied by the EPR technique ${ }^{1,2}$.

The results of the present kinetic study of the thermal recombination of the radicals formed on $\mathrm{Na}_{2} \mathrm{WO}_{4} \cdot 2 \mathrm{H}_{2} \mathrm{O}$ UCB (Union Chimique Belge, Brussels, Belgium) irradiation, are completely different from those obtained for $\mathrm{Na}_{2} \mathrm{WO}_{4} \cdot 2 \mathrm{H}_{2} \mathrm{O}$ supplied by Merck ${ }^{3}$.

This difference in the thermal behavior of the same substance is due to the sample history: its mode of preparation, the absorbed impurities from the synthesis process and its degree of aging.

The influence of the preparation method on the thermal stability of the radicals formed upon irradiation of the same substance prepared in various ways, has been previously found with irradiation of the oxygenated compounds with selenium ${ }^{4}$ and chromium ${ }^{5}$.

The presence of the additions in the form of some ions foreign to the network having different ionic radius and polarizing properties from the principal ion, change both the number and chemical bonds strength and the stability of the radicals. The presence of some foreign cations in the crystalline network can lead either to the decrease, or increase of the stability of the radicals. The existence of the additives from the synthesis process influences the radical stability due to the formation of a supplementary number of cationic and anionic dislocations in the crystal, leading to the increasing or decreasing of the radiolytic stability ${ }^{6}$.

The different thermal behavior of the same radical, formed in the same matrix, may be also due to the microcrystalline structure determined by the macro and micro imperfections from crystal biography $^{7,8}$. Each type of imperfection exhibits a certain influence upon radiolytical stability. 
SOUTH. BRAZ. J. CHEM., Vol.18, No. 18, 2010

M. Contineanu, A.E. Stanciu, I. Contineanu and A. Neacşu

There is no information concerning the $\mathrm{Na}_{2} \mathrm{WO}_{4} \cdot 2 \mathrm{H}_{2} \mathrm{O}$ UCB radiolysis in polycrystalline solid state.

Some information, regarding the process mechanism, has been obtained from the kinetic study of the thermal disappearance of the radicals formed by this substance.

\section{EXPERIMENTAL}

For irradiation were used polycrystalline samples of $\mathrm{Na}_{2} \mathrm{WO}_{4} \cdot 2 \mathrm{H}_{2} \mathrm{O}$ UCB. The irradiations were performed at room temperature by $\gamma$ rays from a ${ }^{137} \mathrm{Cs}$ source with $800 \mathrm{Ci}$ activity and $1.05 \mathrm{~Gy} \mathrm{~h}^{-1}$ dose rate.

EPR spectra of the irradiated samples were recorded with an ART 5 spectrograph (IFIN - Institutul de Fizica si Inginerie Nucleara, Turnu Magurele), operating in the $\mathrm{X}$ band with a $100 \mathrm{kHz}$ high frequency modulation. In order to determine the $\mathrm{g}$ factor $\mathrm{Mn}^{2+}$ ion in $\mathrm{CaO}$ matrix was used as a standard.

\section{RESULTS AND DISCUSSION}

By $\gamma$ irradiation at room temperature of $\mathrm{Na}_{2} \mathrm{WO}_{4} \cdot 2 \mathrm{H}_{2} \mathrm{O} \mathrm{UCB}$ in polycrystalline solid state, wide singlet spectra $(\Delta \mathrm{H}=1.57 \mathrm{mT})$ of small intensity are recorded. In the EPR spectrum shown in Figure 1 the existence of some hyperfine splittings (marked with "a") of four components having an intensity of about $12 \%$ of the singlet can be noted. 
SOUTH. BRAZ. J. CHEM., Vol.18, No. 18, 2010

52

\section{Radiolysis of Sodium Wolframate UCB}

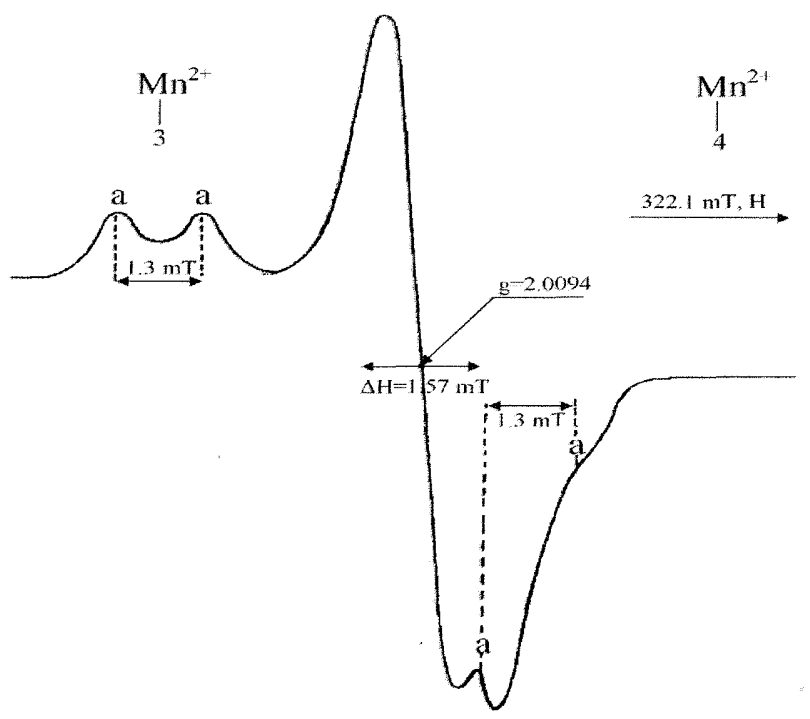

Figure 1.EPR spectrum of a $\mathrm{Na}_{2} \mathrm{WO}_{4} \cdot 2 \mathrm{H}_{2} \mathrm{O}$ UCB polycrystalline sample, $\gamma$ irradiated at room temperature with a dose of $2 \cdot 10^{4} \mathrm{~Gy}$.

For the spectrum interpretation it should be noted that $\mathrm{W}$ has many isotopes with different nuclear spin: the nuclei of ${ }^{180,182,184,186} \mathrm{~W}$ isotopes, with $85.6 \%$ natural nuclear abundance have the nuclear spin equal with zero $(\mathrm{I}=0)$ and the ${ }^{183} \mathrm{~W}$ isotope, with $14.6 \%$ of natural abundance has an unpaired nuclear $\operatorname{spin}(I=1 / 2)$.

It can be noticed that the $14,6 \%$ natural abundance of the ${ }^{183} \mathrm{~W}$ isotope is close to the ratio between the hyperfine lines intensity and singlet intensity. 


\section{Contineanu, A.E. Stanciu, I. Contineanu and A. Neacşu}

The signal from Figure 1 belongs to the $\mathrm{W}^{-}$radical, with $\mathrm{W}$ in VII valence state, similar to $\mathrm{Cr}_{4}^{-}$obtained by $\mathrm{CrO}_{4}^{2-}$ irradiation 9

Zelder and Livingston ${ }^{10}$ proposed the hypothesis that the unpaired electron from the $\mathrm{W}_{\mathrm{O}_{4}^{-}}$center is strongly delocalized, having the possibility to distribute on a $\mathrm{WO}_{4}^{2-}$ neighbor ion to form a center with two $\mathrm{W}$ atoms of the $W \dot{O}_{4}^{-}-W O_{4}^{2-}$ or $\left(W_{2} \dot{O}_{8}\right)^{3-}$ type.

The central singlet with high intensity comes from isotopes species with two nuclei $I=0$, which represent $85.6 \%$.

The formation of the four symmetrical hyperfine splittings from the main line is a confirmation of the hypothesis that the odd electron from $W \dot{O_{4}^{-}}$radical interacts with two ${ }^{183} \mathrm{~W}(\mathrm{I}=1 / 2)$ nonequivalent nuclei. Due to the strongly dipolar interaction that takes place between the radical species in the polycrystalline sample, the hyperfine structure is poorly resolved, leading to an uneven width of spectral lines ${ }^{11}$.

In order to establish the influence of integral dose of irradiation upon $\left(W_{2} \dot{O}_{8}\right)^{3-}$ radical concentration, samples having equal amounts of wolframate have been irradiated at different times. The EPR spectra were recorded under the same conditions. 


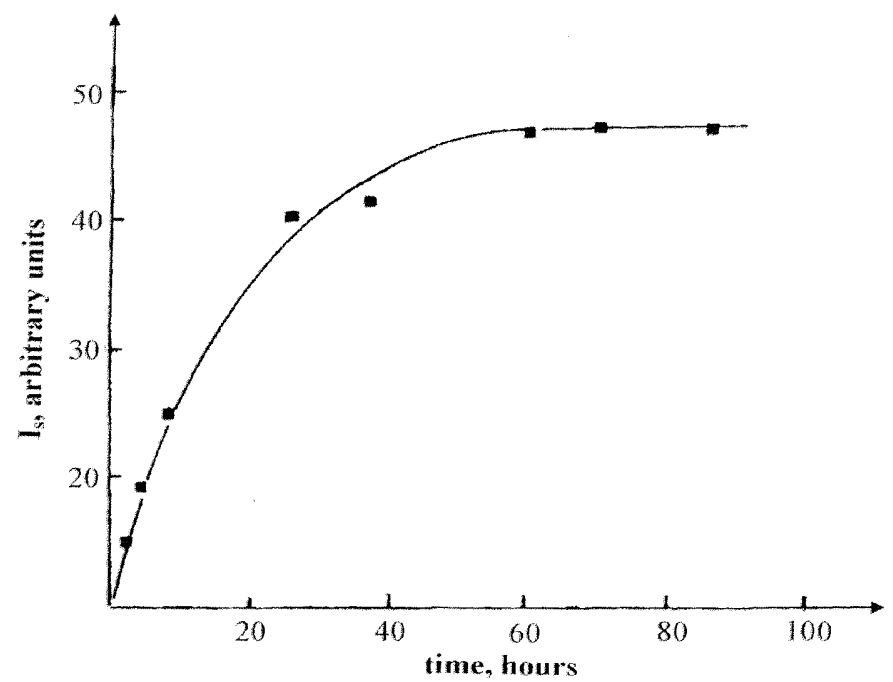

Figure 2. Variation of the relative intensity (Ir) of the EPR signal of $\mathrm{Na}_{2} \mathrm{WO}_{4} \cdot 2 \mathrm{H}_{2} \mathrm{O}$ UCB polycrystalline samples versus irradiation time (dose rate $1.05 \cdot 10^{2} \mathrm{Gyh}^{-1}$ ).

Figure 2 illustrates the variation of the EPR signal intensity versus irradiation time (dose rate $\left.1.05 \cdot 10^{2} \mathrm{Gyh}^{-1}\right)$.

First, it can be noticed that radical concentration increases proportionally with the integral dose up to $2.5 \cdot 10^{3} \mathrm{~Gy}$ and then reaches a plateau.

It is important to explain the causes of the attainment of this stationary state. The migration of the radicals followed by their recombination was suggested ${ }^{12}$. However, this process can not be considered in the solid state at room temperature. More plausible are the following two explanations: the radicals, after their formation, absorb energy from the incident radiation resulting in their destruction. At high irradiation doses the radical concentration increases. Being arranged in 
SOUTH. BRAZ. J. CHEM., Vol.18, No. 18, 2010

M. Contineanu, A.E. Stanciu, I. Contineanu and A. Neacşu

close positions, they interact among themselves producing recombinations. This last hypothesis is supported by the EPR spectral change at higher irradiation doses.

The stability of the $\left(W_{2} \dot{O}_{8}\right)^{3-}$ paramagnetic centers with temperature has been studied by means of reaction isochronous procedure. For this purpose, a $\gamma$ irradiated sample was gradually heated for 5 minutes stepwise (each step $=10^{\circ} \mathrm{C}$ ) from room temperature up to the temperature of the complete radical disappearance. The variation of the EPR signal intensity versus temperature is shown in Figure 3.

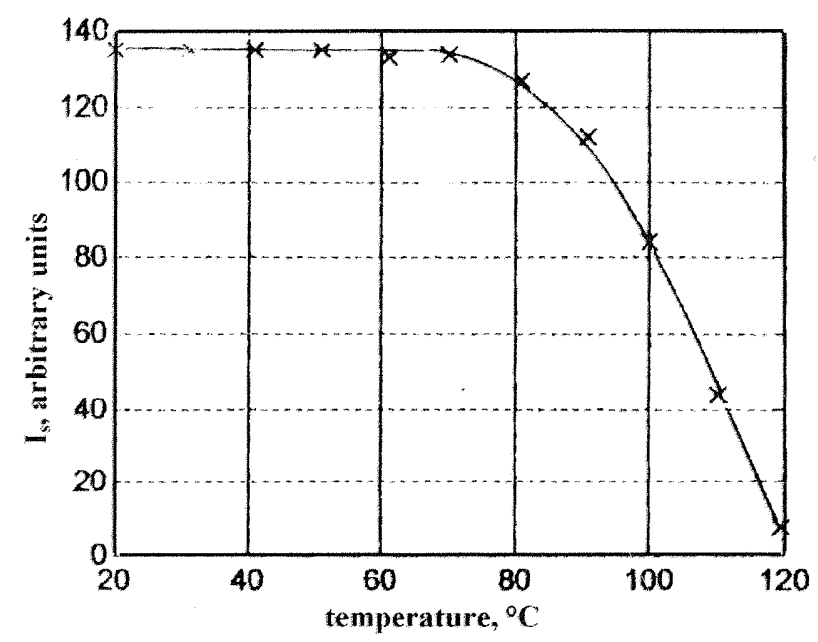

Figure 3. Isochronous variation of EPR signal intensity (arbitrary units) versus heating temperature for a $\gamma$ irradiated $\mathrm{Na}_{2} \mathrm{WO}_{4} \cdot 2 \mathrm{H}_{2} \mathrm{O} \mathrm{UCB}$ sample.

From Figure 3 it can be noted that the EPR signal intensity remains constant up to $70^{\circ} \mathrm{C}$. Subsequently, it decreases linearly with increasing temperature. The complete disappearance occurs at $120^{\circ} \mathrm{C}$. 


\section{SOUTH. BRAZ. J. CHEM., Vol.18, No. 18, 2010}

The kinetic study performed by EPR for the thermal recombination process of the $\left(W_{2} \dot{\mathrm{O}}_{8}\right)^{3-}$ radicals, formed on $\mathrm{Na}_{2} \mathrm{WO}_{4} \cdot 2 \mathrm{H}_{2} \mathrm{O}$ UCB radiolysis, involves the reaction isotherms procedure.

The temperature range, used to calculate the rate constants, has been chosen in order to fulfill two conditions: first, the reaction to occur in proportion to over $50 \%$ and second, the reaction to occur not too fast in order to reduce the experimental errors.

The kinetic study was performed on $80-120^{\circ} \mathrm{C}$ temperature range. The relative intensity $\left(I_{\mathrm{r}}=\mathrm{I}_{\mathrm{t}} / \mathrm{I}_{0}\right.$, where $I_{t}$ represents the intensity at the " $t$ " moment and $I_{0}$ the initial intensity) with the time of isothermal heating is plotted in Figure 4.

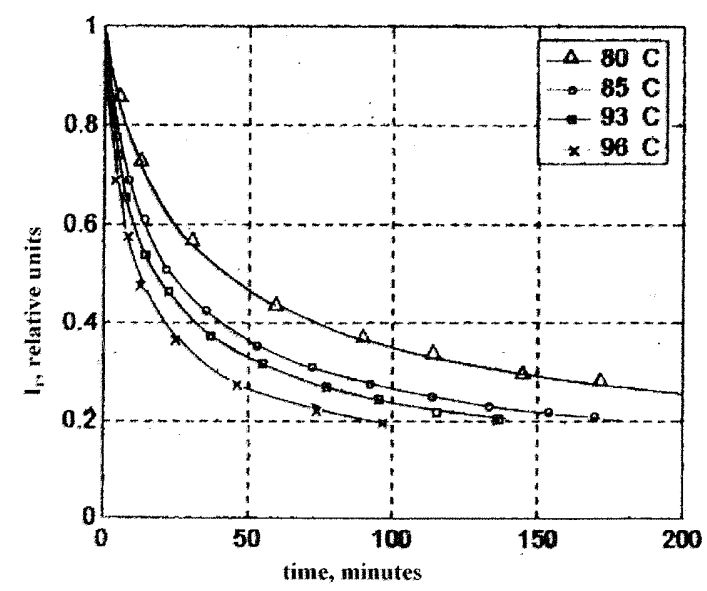

a)

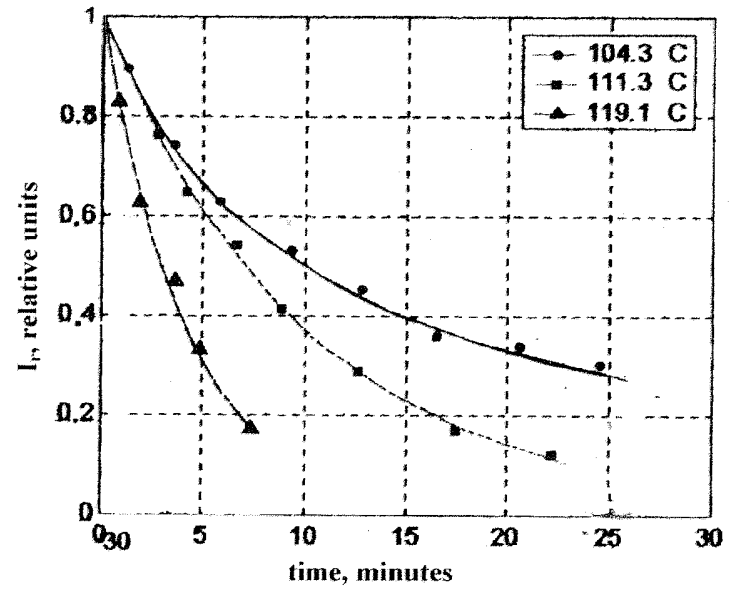

b)

Figure 4. Variation of the EPR signal relative intensity of the irradiated samples and isothermally heated at the temperatures: a) $85-96^{\circ} \mathrm{C}$ b) $104-119^{\circ} \mathrm{C}$.

From the reaction isotherms it can be seen that the radical thermal disappearance rate increases with increasing temperature. All the isotherms tend to a plateau evenly situated that decreases with higher temperature. The plateau appearance proves the fact that radicals have different thermal 
stability. Trapped radicals remain in the crystalline lattice for all temperatures. For these radicals the energy received from exterior is lower than the binding energy.

For the calculation of the rate constants both integral and differential kinetic methods were used. In the integral method, the established equations from chemical kinetics were verified, for all whole and fractional reaction orders, with the specification that the radical concentration changed with the relative intensity of EPR signal $\left(\mathrm{I}_{\mathrm{r}}\right)$.

The graph of each kinetic equation was done in linear form, corresponding for all reaction orders. The straight lines were plotted so that each slope had the least error related to the experimental points.

The experimental points gave the best line for the plot of the third order kinetic equation at $93^{\circ} \mathrm{C}$ temperature (Figure 5), indicating that the thermal disappearance of the radicals follows kinetics of third order.

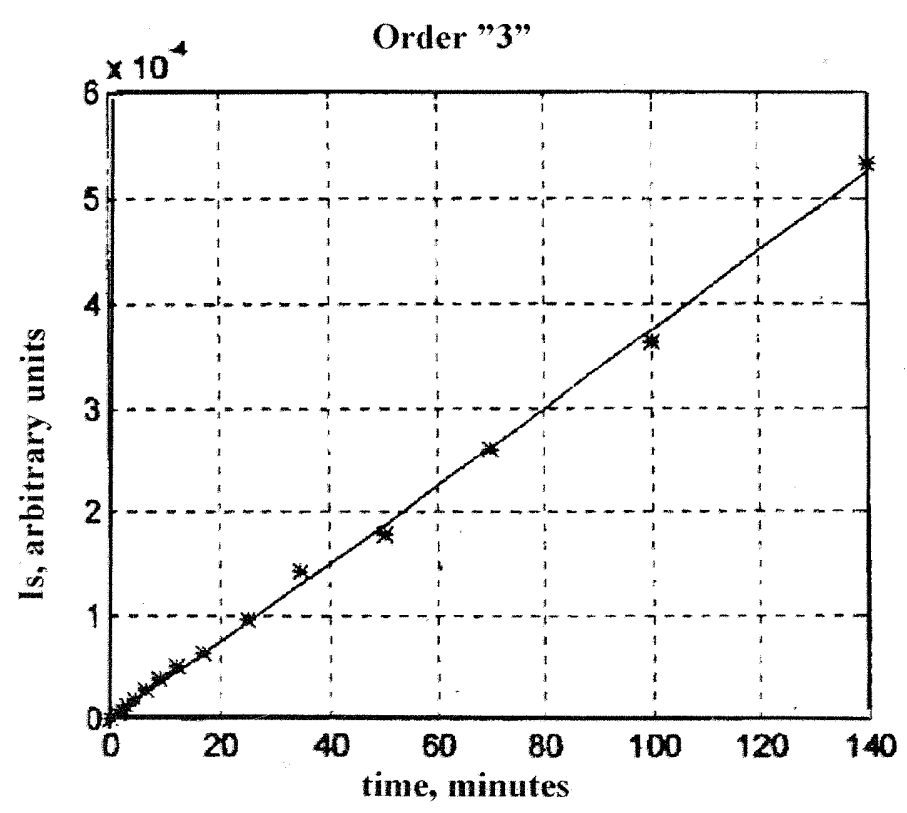

Figure 5. Plot of the kinetic equation corresponding toa reaction of third order, versus the time for isothermal heating at $93^{\circ} \mathrm{C}$ for a $\gamma$ irradiated $\mathrm{Na}_{2} \mathrm{WO}_{4} \cdot 2 \mathrm{H}_{2} \mathrm{OUCB}$ sample. 
Using the graphs corresponding to all reaction orders from 0 to 3 , at $93^{\circ} \mathrm{C}$, the rate constants have been calculated by the least squares method (Table 1).

To verify the reaction of third order, obtained from isotherms plotted for each reaction order, the $\Delta \mathrm{I}_{\mathrm{r}}$ deviation of each experimental point, related to the adequate point on the regression line, was determined (Table 1). The values obtained were related at the last point value on the regression line and in this way, errors in percent $\left(\varepsilon_{\max }\right)$ have been calculated.

Table 1. Kinetic parameters and maximum relative errors determined for $\left(W_{2} \dot{O}_{8}\right)^{3-}$ radical species disappearance at $93^{\circ} \mathrm{C}$, formed on $\mathrm{Na}_{2} \mathrm{WO}_{4} \cdot 2 \mathrm{H}_{2} \mathrm{O} \mathrm{UCB} \gamma$ irradiation.

\begin{tabular}{|c|c|c|c|c|}
\hline $\begin{array}{c}\text { Crt. } \\
\text { No. }\end{array}$ & $\begin{array}{c}\text { Reaction order } \\
\text { "n" }\end{array}$ & $\mathbf{k}\left[\mathbf{s}^{\mathbf{- 1}}\right] \mathbf{x} \mathbf{1 0}^{\mathbf{3}}$ & $\Delta \mathbf{I}_{\mathbf{r}}[\mathbf{u} . \mathbf{r}]$ & $\varepsilon_{\max }[\mathbf{\%}]$ \\
\hline 1 & 0 & 0.14 & 0.36 & 30.54 \\
\hline 2 & 0,5 & 0.18 & 0.41 & 26.45 \\
\hline 3 & 1 & 0.25 & 0.47 & 22.37 \\
\hline 4 & 1,5 & 0.36 & 0.54 & 17.84 \\
\hline 5 & 2 & 0.54 & 0.58 & 12.77 \\
\hline 6 & 2,5 & 0.86 & 0.54 & 7.46 \\
\hline 7 & 3 & 1.41 & 0.26 & 2.23 \\
\hline 8 & 3,5 & 2.40 & 1.71 & 8.84 \\
\hline 9 & 4 & 4.24 & 5.71 & 16.04 \\
\hline
\end{tabular}

The maximum relative error $\left(\varepsilon_{\max }\right)$ versus reaction order, for $93^{\circ} \mathrm{C}$ isotherm is plotted in Figure 6 . 


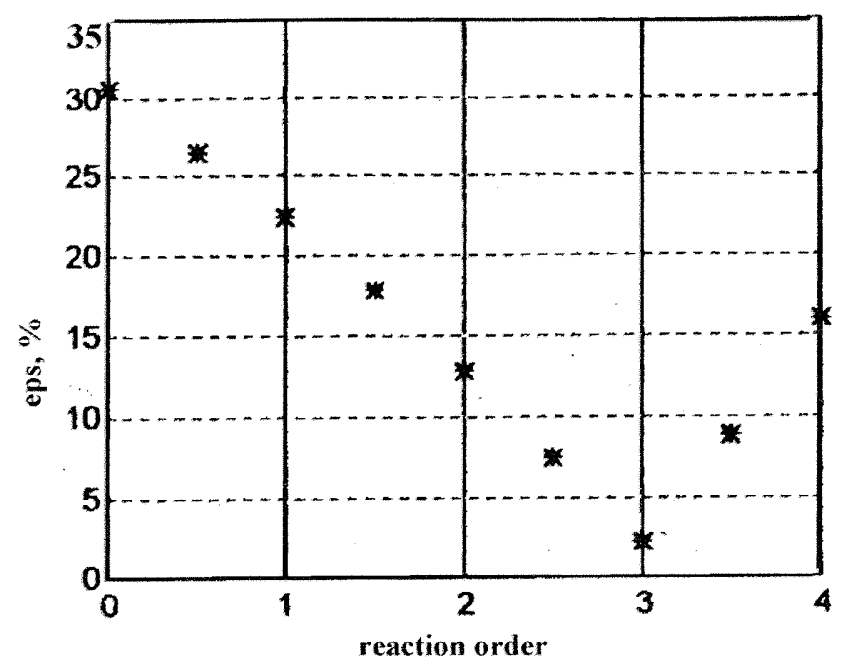

Figure 6. Variation of the maximum relative error in percent, versus the reaction order for the $93^{\circ} \mathrm{C}$ isotherm of a $\gamma$ irradiated $\mathrm{Na}_{2} \mathrm{WO}_{4} \cdot 2 \mathrm{H}_{2} \mathrm{O} \mathrm{UCB}$ sample.

It can be noted that the maximum relative error $\varepsilon_{\max }$ linear decreases with increase of reaction order, reaching a minimum value at order 3 and subsequently it increases linearly. The same behavior was observed for all isotherms as a function of reaction order.

The differential method was also used for the determination of reaction order and the calculation of rate constants corresponding to radical thermal disappearance.

The logarithm of the rate of radical disappearance $\ln (-\mathrm{dIr} / \mathrm{dt})$ versus the logarithm of the relative intensity $\ln$ Ir of EPR signals at $93^{\circ} \mathrm{C}$. is illustrated in Figure7. 


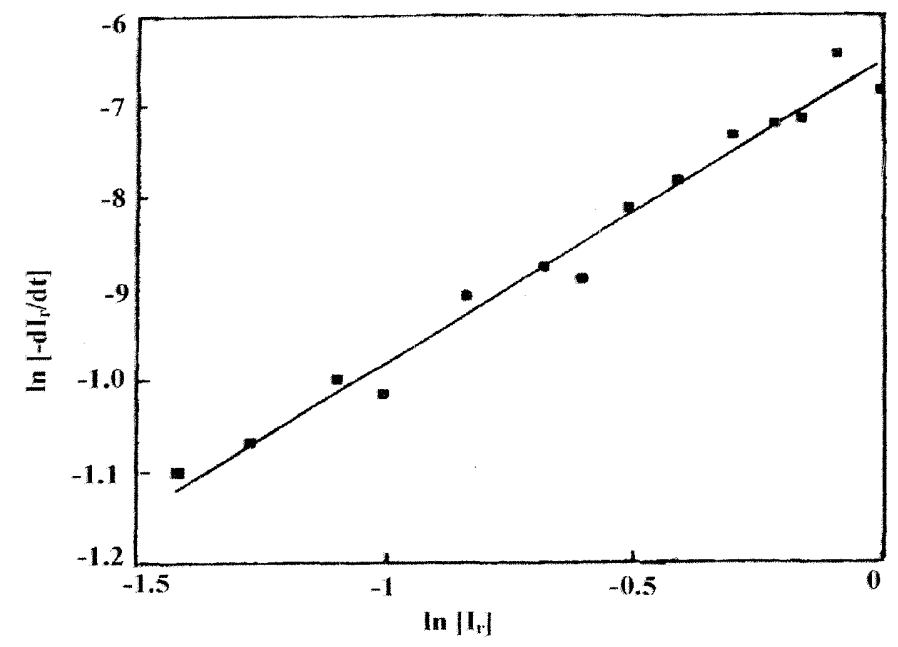

Figure 7.Variation of the logarithm rate of radical disappearance, versus the logarithm the relative intensity of EPR signals $\left(\mathrm{I}_{\mathrm{r}}\right)$ at $93^{\circ} \mathrm{C}$ for a $\gamma$ irradiated $\mathrm{Na}_{2} \mathrm{WO}_{4} \cdot 2 \mathrm{H}_{2} \mathrm{O}$ UCB sample.

Using the integral method, the reaction order determined was 3 and the rate constant $\mathrm{k}=1.41 \cdot 10^{-3} \mathrm{~s}^{-1}$ By the differential method, the reaction order was 3.28 and the rate constant $\mathrm{k}=1.47 \cdot 10^{-3} \mathrm{~s}^{-1}$. The agreement between the two methods is satisfactory.

The kinetic parameters corresponding to the radical thermal disappearance at different temperatures are presented in Table 2.

VISIT OUR SITE: http://www.sbjchem.he.com.br 
Table 2. The kinetic parameters for $\left(W_{2} \dot{O}_{8}\right)^{3-}$ radical species disappearance at different temperatures formed upon $\mathrm{Na}_{2} \mathrm{WO}_{4} \cdot 2 \mathrm{H}_{2} \mathrm{O} \mathrm{UCB}$ radiolysis.

\begin{tabular}{|c|c|c|c|c|c|c|c|c|}
\hline $\begin{array}{c}\text { Reaction } \\
\text { order } \\
\text { "n" }\end{array}$ & $\mathbf{t}\left[{ }^{\circ} \mathbf{C}\right]$ & $\mathbf{T}[\mathrm{K}]$ & $\begin{array}{c}\left.1 / T \mathbf{K}^{-1}\right] \mathbf{x} \\
10^{3}\end{array}$ & $\begin{array}{c}k\left[s^{-1}\right] x \\
10^{3}\end{array}$ & $\operatorname{lgk}+3$ & $A\left[s^{-1}\right]$ & Ea[kJ/mol] & $\begin{array}{c}\Delta \mathbf{S}^{*} \\
\mathbf{J} / \mathbf{m o l} \cdot \mathbf{K}\end{array}$ \\
\hline \multirow{4}{*}{3} & 80 & 353.15 & 2.8316 & 0.61 & -0.21 & $0.99 \cdot 10^{8}$ & \multirow{4}{*}{75.78} & \multirow{4}{*}{-117.6} \\
\hline & 85 & 358.15 & 2.7921 & 1.11 & 0.046 & $1.27 \cdot 10^{8}$ & & \\
\hline & 93 & 366.15 & 2.7311 & 1.41 & 0.15 & $0.92 \cdot 10^{8}$ & & \\
\hline & 96 & 369.15 & 2.7089 & 2.19 & 0.34 & $1.17 \cdot 10^{8}$ & & \\
\hline 2 & 104.7 & 377.85 & 2.6465 & 1.69 & 0.23 & - & & \\
\hline \multirow[t]{2}{*}{1} & 111.3 & 384.45 & 2.6611 & 1.65 & 0.22 & - & & \\
\hline & 119.1 & 392.25 & 2.5493 & 3.95 & 0.60 & - & & \\
\hline
\end{tabular}

Analysing the results from Table 2 it can be noted that for the process studied for the recombination of radicals with an increasing temperature interval of $40^{\circ} \mathrm{C}$, the reaction order decreased from 3 to 1 .

Using the kinetic data corresponding to third order kinetics for radical disappearance, the Arrhenius plot was done. (Figure 8).

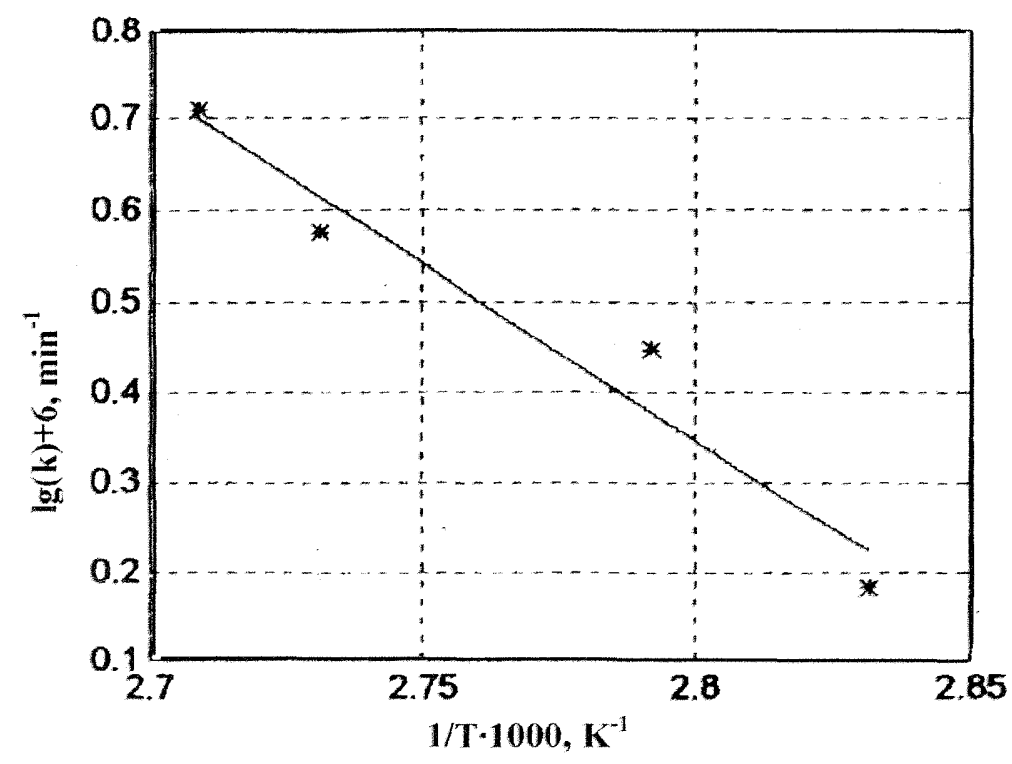

Figure 8. Arrhenius plot for the radical thermal disappearance in the temperature range 80$96^{\circ} \mathrm{C}$ for $\mathrm{Na}_{2} \mathrm{WO}_{4} \cdot 2 \mathrm{H}_{2} \mathrm{O} \mathrm{UCB} \gamma$ irradiated sample. 
From the slope of the straight line, presented in Figure 8, an activation energy $\mathrm{Ea}=75.78 \mathrm{~kJ} / \mathrm{mol}$ and a pre-exponential factor $\mathrm{A}=1.08 \cdot 10^{8} \mathrm{~s}^{-1}$ were calculated.

We mention that these values do not have the same meaning as those from the theory of the gas state collisions.

In this case, the reactant entities, the radicals respectively, do not move freely as gas molecules and the recombination process takes place only after the increase of the mobility of these species due to the temperature. Knowing the pre-exponential A factor, the activation entropy

$\Delta S^{*}=-117.6 \mathrm{~J} / \mathrm{mol} \cdot \mathrm{K}$, for the third order, using the formula: $\Delta S^{*}=R\left[\ln \frac{A h}{k_{B} T}-m\right]$,

where, $\mathrm{h}=6.625 \cdot 10^{-3} \mathrm{~J} \cdot \mathrm{s}, \mathrm{k}_{\mathrm{B}}=1.38 \cdot 10^{-23} \mathrm{~J} / \mathrm{K}, \mathrm{R}=8.31 \mathrm{~J} / \mathrm{mol} \cdot \mathrm{K}$ and $\mathrm{m}=3$ was calculated.

The high and negative value of the activation entropy means that the activated complex has a more ordered structure than the reactants. The involvement of the three radicals in the reaction is accompanied by loss of the rotational and translational degrees of freedom.

The kinetics of third order indicates that the recombination process mechanism is a complicated one. The $\mathrm{W}_{4}^{-}$species disappear by a sequence of several possible reactions, so that the overall third order process is equal to that found experimentally.

$$
\begin{aligned}
& \rightarrow 2 \mathrm{WO}_{3}+\mathrm{O}_{2}^{2-} \\
& W \dot{\mathrm{O}_{4}^{-}}+\mathrm{W} \dot{\mathrm{O}_{4}^{-}}-1 \\
& \rightarrow \mathrm{WO}_{4}^{2-}+\mathrm{WO}_{3}+\mathrm{O} \\
& \mathrm{W}_{\mathrm{O}_{4}^{-}}+\mathrm{WO}_{4}^{2-} \rightarrow \mathrm{WO}_{3}+\mathrm{WO}_{2}+\mathrm{O}_{2}^{2-}+{\dot{O^{-}}}^{-}
\end{aligned}
$$

The decrease of reaction order from 3 to 1 , with increasing temperature indicates that some of the reactions become dominant in a temperature range, determining the overall order. 
SOUTH. BRAZ. J. CHEM., Vol.18, No. 18, 2010

The first order reaction consists of $\mathrm{W}_{4}^{-}$species decomposition, with oxygen ejection and tungsten oxides formation:

$$
\begin{aligned}
& \rightarrow W O_{3}+\dot{O^{-}} \\
& W \dot{O}_{4}^{-}-1 \\
& \rightarrow \mathrm{WO}_{2}+\dot{\mathrm{O}_{2}^{-}}
\end{aligned}
$$

The electrons trapped in the crystalline lattice become mobile by heating and they could be trapped by the $W^{-}$species to remake the initial ion.

$$
\mathrm{W}_{4}^{-}+\bar{e} \rightarrow W O_{4}^{2-}
$$

\section{CONCLUSIONS}

The radiolysis at room temperature in polycrystalline solid state of $\mathrm{Na}_{2} \mathrm{WO}_{4} \cdot 2 \mathrm{H}_{2} \mathrm{O}$ UCB was studied.

The EPR spectra recorded for the irradiated samples belong to the $\left(W_{2} \dot{O}_{8}\right)^{3-}$ radical that is stable at room temperature. From the kinetic study with increasing temperature, a decrease of the reaction order from 3 to 1 for the radical thermal annealing process was observed. The mechanism proposed for the radiolytic formation of radicals and radical thermal recombination is in agreement with the kinetic results. 


\section{REFERENCES}

1. P.V. Solnteva and I.M. Seerbacova, J.Str.Him.12, 3, 397-402 (1971).

2. O. Constantinescu, I. Pascaru, M. Constantinescu and M. Arizan, Rev.Roum.Phys. 17, 1, 3945 (1972).

3. M. Contineanu, A. Stanciu and A. Neacsu, Rev.Roum.Chim.55, 8, 467-474 (2010).

4. M. Contineanu and E.N. Hristea, Rev.Chim.(Bucharest) 51, 1, 45-50 (2000).

5. M. Contineanu and A. Comaniciu, Rev.Chim.(Bucharest) 47, 2,139-142 (1996).

6. M. Contineanu and F. Zalaru, Rev.Chim (Bucharest) 56, 10, 1014-1017 (2005).

7. .N. Kurilenko, E.I. Saunin and V.V. Gromov, J.Fiz.Him. 58, 5, 1095-1099 (1984).

8. M. Contineanu, Rev.Chim.(Bucharest) 50, 4, 270-275 (1999).

9. M. Contineanu and A. Stanciu, Anal.Univ.Bucharest V, 43-49 (1996).

10. H. Zeldes and R. Livingston, J.Chem.Phys.34, 1 ,247-252 (1961).

11. R.P. Edwards, S. Subramanian and R.C.M. Symons, J.Chem.Phys.47, 3772-3780 (1967).

12. P.A. Kushelevsky and A.M. Slifkin, Rad.Effects 14, 67-72 (1972).

VISIT OUR SITE: http://www.sbjchem.he.com.br 